\title{
Del Pazo de Meirás a la Matanza de Oseira: intervención educativa sobre memoria, patrimonio y conflicto
}

\author{
Ana PEDROUZO FARIÑA \\ Belén CASTRO-FERNÁNDEZ
}

Datos de contacto:

Ana Pedrouzo Fariña

Maestra de Educación Primaria ana.pedrouzo@rai.usc.es

Belén Castro-Fernández Universidad de Santiago de Compostela

belen.castro@usc.es

Recibido: 26/09/2021

Aceptado: 19/11/2021

\begin{abstract}
RESUMEN
Se presentan resultados de una intervención en educación primaria sobre el Pazo de Meirás, el que fuera residencia del dictador Franco en Galicia, para orientar a la ciudadanía en la resignificación y transmisión patrimonial. La dimensión conflictiva de este lugar lo convierte en un recurso clave para despertar emociones, desarrollar el pensamiento social y crítico, e implementar un modelo de acción, defensa, y recuperación de la memoria entre los estudiantes. Para estimular un aprendizaje significativo la intervención se dividió en dos partes. La primera se centró en Meirás, como aproximación a un modelo crítico de enseñanza y aprendizaje sobre temas controversiales. A continuación, se implementó lo aprendido sobre un conflicto patrimonial próximo al centro educativo, con intervención en la comunidad local. Desde un enfoque cualitativo se evaluó y midió el potencial de la experiencia y su impacto social, así como el grado de compromiso adquirido por los estudiantes con el patrimonio. Los resultados informan que el modelo Meirás, centrado en metodologías activas de aprendizaje y en la indagación a través del debate y el consenso, contribuye a: desarrollar la competencia patrimonial del alumnado; recuperar la historia y la memoria local de manera contextualizada con implicación de los distintos agentes comunitarios; y reforzar la comprensión y conexión con el entorno.
\end{abstract}

PALABRAS CLAVE: educación patrimonial; competencia patrimonial; patrimonio controversial; educación basada en el lugar; franquismo. 


\title{
From the Pazo de Meirás to the Oseira's Crime: educational intervention about memory, heritage and conflict
}

\begin{abstract}
Results of an intervention in primary education on the Pazo de Meirás, which was the residence of the dictator Franco in Galicia, are presented to guide citizens in the redefinition and transmission of assets. The conflictive dimension of this place makes it a key resource to awaken emotions, develop social and critical thinking, and implement a model of action, defense, and memory recovery among students. To stimulate meaningful learning, the intervention was divided into two parts. The first focused on Meirás, as an approach to a critical teaching and learning model on controversial issues. Next, what was learned about a patrimonial conflict near the educational center was implemented, with intervention in the local community. From a qualitative approach, the potential of the experience and its social impact, as well as the degree of commitment acquired by the students with heritage, was evaluated and measured. The results report that the Meirás model, focused on active learning methodologies and inquiry through debate and consensus, contributes to: developing the patrimonial competence of students; recover local history and memory in a contextualized way with the involvement of the different community agents; and reinforce understanding and connection with the environment.
\end{abstract}

KEYWORDS: heritage education; cultural heritage competence; controversial heritage; place-based education; Franco's dictatorship.

\section{Introducción}

¿En qué medida un lugar instrumentalizado por la dictadura franquista como el Pazo de Meirás permite implementar un modelo crítico de enseñanza y aprendizaje, orientado a la re-significación patrimonial? El eje vertebrador de este estudio parte del dilema que gira en torno a Meirás, que fuera residencia de Franco en Galicia desde los años cuarenta, un lugar de memoria socialmente conflictivo con gran repercusión en los últimos años (Babío y Pérez, 2017) donde confluyen intereses políticos, culturales y de memoria histórica. Después de ochenta y dos años de su expolio, y tras un proceso de movilización paulatino y constante (Souto, 2019), la ciudadanía consigue denunciar la apropiación ilegal del pazo ocurrida en 1941, rescatarlo y abrir el debate sobre su uso público. Esta estrategia, que conduce a la recuperación del pazo y que marca un referente de la participación plural y colectiva del pueblo bajo procesos pacíficos y democráticos, se conoce como "metodología Meirás" (Souto, p. 48).

Este modelo de compromiso ciudadano, junto a experiencias didácticas realizadas en torno a otro contexto abatido por el franquismo como es la localidad de Portomarín (Castro, López-Facal et al., 2021), se toman como base para diseñar y llevar a cabo una experiencia educativa sobre Meirás en un centro rural de Galicia por su potencialidad 
formativa: a) se trata de un conflicto candente, en plena efervescencia social; b) ha resurgido gracias a la intervención social del pueblo; c) está cargado de simbologías; d) es complejo, dada la confluencia de concepciones que permiten abordarlo desde concepciones diferentes, incluso contrapuestos, que permiten suscitar el debate en el aula y proponer soluciones basadas en la argumentación y en valores éticos; e) en torno a él se tejen unos fuertes vínculos patrimoniales, capaces de unir a una comunidad que lucha por su resignificación

Meirás sigue alentando discursos políticos por su efecto propagandístico y su simbolismo nacional, dejando de lado la experiencia subjetiva de cada individuo, que es la que realmente tiene la capacidad de determinar la existencia del elemento patrimonial (Castro, Jiménez et al., 2021). Desde la restauración de la Democracia en España ha habido un debate, intensificado en los últimos años, sobre qué hacer con esa incómoda herencia, ya que en la Transición se decidió olvidar el período de la Dictadura, y obviar su significado y uso político, a pesar de permanecer presente en toponimia, calles, monumentos, celebraciones... (de Andrés, 2006). Se prefirió no alterar y mantener la memoria de quienes apoyaron al dictador, relegando los derechos de las víctimas bajo la extraordinaria habilidad del régimen para generar una memoria justificativa, autoindulgente y resistente con una gran aliada para su supervivencia: las políticas del olvido (Domínguez y Riveiro, 2020, p. 30). En el año 2002 comenzaron a aprobarse las primeras leyes que abogaban por la memoria de las víctimas de la Guerra Civil, el Franquismo y la Transición; pero no fue hasta 2007 cuando se aprobó la Ley de Memoria Histórica (Ley, 52/2007) en la que se reconocían y ampliaban sus derechos (de Andrés, 2006). Aunque la retirada de símbolos del Franquismo se aprecia sobre todo en el callejero, estas referencias todavía son numerosas en pueblos y ciudades (Duch, 2002). En mayor o menor medida, nombres como Calvo Sotelo, Franco, militares franquistas u otros locales sigue formando parte del nomenclátor (de Andrés, 2006). La supervivencia, cuatro décadas después, de este tipo de marcadores simbólicos franquistas demuestra las insuficiencias y debilidades de las memorias democráticas (Rina, 2019, p. 196). Con todo, estas leyes han sido lentas y contradictorias en cuanto a la riqueza vinculada con el dictador (Núñez, 2019), conformando un tema delicado y difícil de abordar todavía en la actualidad, dando lugar a la deriva del movimiento memorialista que ha contribuido a la aparición de agentes que han dañado la dimensión cívica de la memoria (Domínguez y Riveiro, 2020, p. 31). Sirva de referencia las tensiones generadas durante su exhumación en el Valle de los Caídos ocurrida en 2019.

En los últimos años, se intensifica un debate impulsado por la necesidad de recuperar la memoria histórica, en el que las huellas de la Guerra Civil y la dictadura franquista tuvieron y siguen teniendo gran repercusión. En el diálogo sobre Meirás, Núñez (2019) presenta dos alternativas: condenar o resignificar. Si nos trasladamos a la antigua Roma, podríamos aplicar lo que se llamó Damnatio Memoriae o condenación de la memoria, que consistía en arrojar al olvido a un enemigo del Estado tras su muerte, lo que incluía eliminar imágenes, monumentos, inscripciones e incluso la prohibición de usar su nombre. Núñez (2019) explica como muchos países alternan esta práctica con la musealización de espacios, por su poder de atracción, dándoles un 
nuevo significado a favor de la memoria y la cultura histórica. Tenemos el ejemplo de Austria, país natal de Hitler que "sigue optando por el silencio incómodo" (Núñez, p. 19), mientras que Alemania pasó de ignorar los lugares asociados al dictador a desarrollar, a principios de los ochenta, "una política de la memoria, abiertamente crítica y proactiva" (Núñez, p. 16), apostando por la re-significación de su patrimonio. Hasta entonces, muchos de esos lugares habían permanecido en el abandono y otros atraían a curiosos motivados por el morbo del Holocausto. Es el caso de las ruinas de la antigua Braunes Haus (casa parda) situada en Munich. Este palacio, reconvertido en 1931 en sede central del NSDAP (conocido coloquialmente como partido nazi alemán) fue abandonado hasta el 2007, albergando en la actualidad el Centro de Documentación sobre el Nazismo (Núñez, 2021). El Pazo de Meirás, a pesar de ser símbolo de la dictadura y del olvido, pero también de la reivindicación histórica, es un lugar vinculado a la escritora y feminista Emilia Pardo Bazán. Ni la memoria democrática debe olvidar el franquismo, ni la memoria cultural la aportación de esta pionera del feminismo. Esto explica que para su nuevo uso en algún sector se apueste por un centro de interpretación patrimonial que integre toda su historia, desde Pardo Bazán hasta los herederos del dictador, y que con ello se consiga difundir valores democráticos (Núñez, 2019).

Cuando hablamos de patrimonio estamos haciendo referencia, de manera implícita, al resultado de un proceso que nace de la creación de vínculos entre un sujeto, individual o colectivo, y un elemento (Fontal, 2003; 2020). Impregnado de un fuerte carácter actitudinal y emocional, el proceso de patrimonialización e identificación con un determinado bien debe ser abordado desde una perspectiva holística, individual y social (Gómez, 2014), ya que el patrimonio fue, y sigue siendo, inherente a la vida de las sociedades, producido por y para las personas, en consonancia con sus inquietudes y vivencias coetáneas (Harvey, 2001). Es la propia sociedad la que decide sobre los elementos que lo conforman, según sus experiencias vitales y valores (Josefsson y Aronsson, 2016). Este dinamismo, implícito en la concepción de patrimonio, determina que cualquier elemento, tanto de naturaleza material como inmaterial, pueda ser modificado, reparado, negociado, disputado, reinterpretado, rechazado e, incluso, recuperado, en lo que a su estatus patrimonial se refiere. Es por ello que desde la escuela se deben impulsar proyectos que desarrollen la iniciativa del alumnado a la intervención social; que contribuyan a la recuperación de su patrimonio; que fomenten el respeto hacia sus diferentes interpretaciones, estableciendo procedimientos de conciliación que ayuden a gestionar problemas sociales y a desarrollar actitudes cívicas y pacíficas mediante procesos deliberativos, de entendimiento mutuo (Consejo de Europa, 2005; Jiménez y Felices, 2018). A través del conocimiento, análisis, reflexión y aportación al alumnado de herramientas y recursos sobre cómo afrontar temas controversiales, se contribuye a la formación de una sociedad democrática (LópezFacal y Santidrián, 2011). La adquisición de valores solo puede abordarse desde la práctica, por lo que el patrimonio socialmente conflictivo permite trabajarlos a través del diálogo en el aula (Rodríguez y López, 2013).

Desde la educación patrimonial se pueden trabajar con distintos tipos de vínculos o nudos patrimoniales (Tabla 1) que, aislados o combinados, atienden a cuatro ámbitos 
que van desde lo cercano a lo lejano y de lo individual a lo social (Fontal y Marín, 2018). Los más fuertes se corresponden con las dimensiones vivencial y afectiva, que son las que en el caso de Meirás impulsaron a los vecinos a la recuperación de la memoria local. Este posicionamiento es clave en el trabajo de sensibilización patrimonial, pues para fortalecer o crear nudos se deben recrear y promover experiencias y emociones en los ciudadanos (Castro y López-Facal, 2019). Partiendo de esos ámbitos patrimoniales, el presente estudio se sitúa, fundamentalmente, en las esferas identitaria y temporal, pues el pazo ha ido adquiriendo a lo largo de los años diferentes significaciones: a) símbolo literario y cultural (figura de Emilia Pardo Bazán), b) símbolo franquista (dictadura y caudillo); c) símbolo de cohesión social (pueblo gallego frente herederos de Franco); d) símbolo democrático (deuda moral con las víctimas del franquismo).

\section{Tabla 1}

Esferas patrimoniales y tipos de vínculos asociados a cada una con ejemplos

\begin{tabular}{lll}
\hline Esferas & Vínculos & Ejemplos \\
\hline Identitaria & identitario, social y religioso & cruz, escudo, bandera \\
Temporal & pasado/infancia & guerra civil \\
Afectiva & afectivo, familiar y amistoso & abuelos/as, vecinos/as \\
Experiencial & experiencial y espacial & expropiación del hogar \\
\hline
\end{tabular}

Nota: Elaborado a partir de Fontal y Marín (2018) sobre el Pazo de Meirás.

\section{Objetivos de la investigación}

El objetivo general de este estudio es comprobar en qué medida el tratamiento de temas controversiales en el aula, como el Pazo de Meirás, contribuye al desarrollo de la llamada competencia patrimonial: "La relación y construcción de significado del individuo y la sociedad con los elementos heredados y generados por la propia cultura y por otras culturas, en tanto se establezcan las relaciones en base en la propiedad simbólica, pertenencia e identidad" (Gómez, 2014: 1054).

Los objetivos específicos (OE) son:

OE1. Identificar la percepción del alumnado sobre patrimonio.

OE2. Desarrollar el pensamiento crítico del alumnado a través de patrimonios conflictivos: el Pazo de Meirás.

OE3. Analizar la re-significación del patrimonio conflictivo local por parte del alumnado mediante una intervención social: la Matanza de Oseira.

\section{Método}

La hipótesis se basa en que una intervención educativa desarrollada sobre un patrimonio socialmente conflictivo, como el Pazo de Meirás, contribuye a que el alumnado de educación primaria adquiera herramientas para comprender y resignificar otros elementos, lugares y memorias, ocultas u ocultadas, de su propio 
entorno a través de una intervención social significativa.

Se lleva a cabo una investigación de carácter cualitativo para la obtención de conocimiento y comprensión del fenómeno a estudiar (Campoy y Gomes, 2009). El análisis de algunos datos se realiza a través de su tratamiento cuantitativo con representación gráfica, y se crean nubes de palabras de diferente tamaño según la frecuencia de los términos recabados.

La muestra está formada por catorce estudiantes, seis niñas y siete niños,

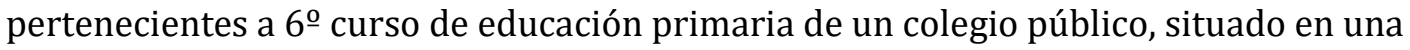
zona rural de la provincia de Ourense. Tres de ellos tienen necesidades educativas específicas. Con edades comprendidas entre 11 y 13 años, habitan en el entorno del centro, excepto dos que viven en Ourense (capital).

Se diseñaron tres instrumentos ad hoc para la recogida de datos, cuyos aspectos formales y de contenido fueron validados por tres expertas en educación patrimonial, a fin de conseguir su mejor adecuación a los objetivos del estudio. Se han seguido los protocolos sobre protección de datos, confidencialidad y procedimientos relacionados con las investigaciones con menores de edad (AEPD, 2018): se cuenta con la autorización de las familias para la utilización de los datos obtenidos en las encuestas realizadas.

- Cuestionario pretest: cumplimentado al inicio del proyecto, compuesto por doce cuestiones, seis estructuradas y seis semi-estructuradas, referidas a conocimientos previos sobre patrimonio y su uso en las aulas.

- Cuestionario postest: cumplimentado al final del proyecto, contiene las preguntas del pretest junto con tres preguntas a mayores para medir el grado de consecución de los objetivos propuestos, una estructurada y dos semiestructuradas.

- Asamblea escolar: centrada en deliberar cuestiones controversiales en torno al conflicto de Meirás, para comprobar el grado de competencia patrimonial y pensamiento social del alumnado a partir de cinco preguntas. Se registró en vídeo para proceder a su análisis detallado.

De forma complementaria, se recogieron producciones de los estudiantes para contrastar datos y conclusiones con el impacto de la experiencia didáctica.

\section{Procedimiento}

La intervención didáctica se desarrolló a lo largo de quince sesiones, de manera interdisciplinar entre las áreas de Ciencias Sociales y Lengua Gallega, con colaboraciones puntuales de otras disciplinas. Desde un enfoque activo, dentro del constructivismo social de Vygotsky (1978), el proyecto estuvo organizado en tres fases:

Fase 1. Punto de partida. Tras el pretest se realizaron actividades para que el alumnado fuese construyendo y asentando, de manera significativa, las bases conceptuales con respecto al concepto de patrimonio.

Fase 2. Desarrollo del proyecto educativo sobre patrimonios conflictivos. La estrategia metodológica clave fue la asamblea de aula (Freinet, 2005), a través de un 
enfoque comunicativo (Rodríguez y López, 2013), donde el alumnado, de manera cooperativa, pudo desarrollar habilidades para tomar decisiones, gestionar polémicas y construir sus opiniones y actitudes. El Pazo de Meirás, como elemento patrimonial controversial, permitió desarrollar una actitud comprometida y responsable del alumnado, así como aplicar pautas de investigación y confrontación en el aula. A partir de este estudio de caso, el alumnado decidió investigar un episodio doloroso y traumático del pasado local, que aún sigue creando malestar entre la población. Se trata de la llamada "Matanza de Oseira" ocurrida en el año 1909 como consecuencia de la defensa del baldaquino que cubría el altar mayor del monasterio emplazado en ese lugar y que culminó con la muerte de nueve vecinos y vecinas a manos de un grupo de guardias civiles convocados por el obispo de Ourense (Cabo y Rodríguez, 2019). De acuerdo con Sánchez y Murga (2019) y en línea con la UNESCO (2012) se asume el aprendizaje basado en la realidad local (Place Based Learning) como un enfoque pedagógico multidisciplinar favorable, que crea y refuerza vínculos comunitarios y fomenta la participación democrática de las personas. Todo ello bajo tres premisas: desarrollo sostenible, cobertura de necesidades sociales y formación de una ciudadanía activa que acerque medidas de intervención social (Fernández, 2020). De este modo, el alumnado utilizó estrategias de indagación, involucrándose en actividades de resolución de problemas de manera creativa, mediante una docencia guiada entre los paradigmas crítico y reflexivo (Santiesteban y Pagès, 2011), apelando a la flexibilidad del proyecto.

Fase 3. Evaluación de la intervención social y postest. En esta fase se evaluaron las producciones del alumnado para la defensa de su patrimonio local, que fueron: a) un podcast sobre la historia de lo ocurrido en la "Matanza de Oseira", como patrimonio incómodo del entorno inmediato, y entrevistas a personas de la localidad conocedoras del suceso; b) un acto en homenaje a las víctimas de ese suceso, con instalación de una placa conmemorativa en el centro escolar; c) un vídeo en memoria de las víctimas; y d) un repositorio de recursos en la WebQuest creada para guiar al alumnado durante el proyecto educativo, con toda la información recabada y las creaciones de los escolares.

\section{Resultados}

\section{OE1. Identificar la percepción del alumnado sobre patrimonio}

La intervención educativa ha contribuido a modificar la concepción inicial del alumnado sobre patrimonio para concretarla en una perspectiva simbólica, asociada a palabras como "vínculo", "nuestro" y "recuerdos". La incidencia de la experiencia en este cambio se observa, además, en la comprensión de patrimonio desde un enfoque humano y vivencial (Figura 1). Esta tendencia se corrobora al preguntar por la importancia auto-adjudicada a los términos indicados, ya que se transita desde la prevalencia de "monumentos, “ayuntamiento", "vivir" y "cultura" en el pretest, a "vínculos", "recuerdos" e "importante" en el postest. 


\section{Figura 1}

Palabras asociadas con patrimonio en pretest (izquierda) y postest (derecha)
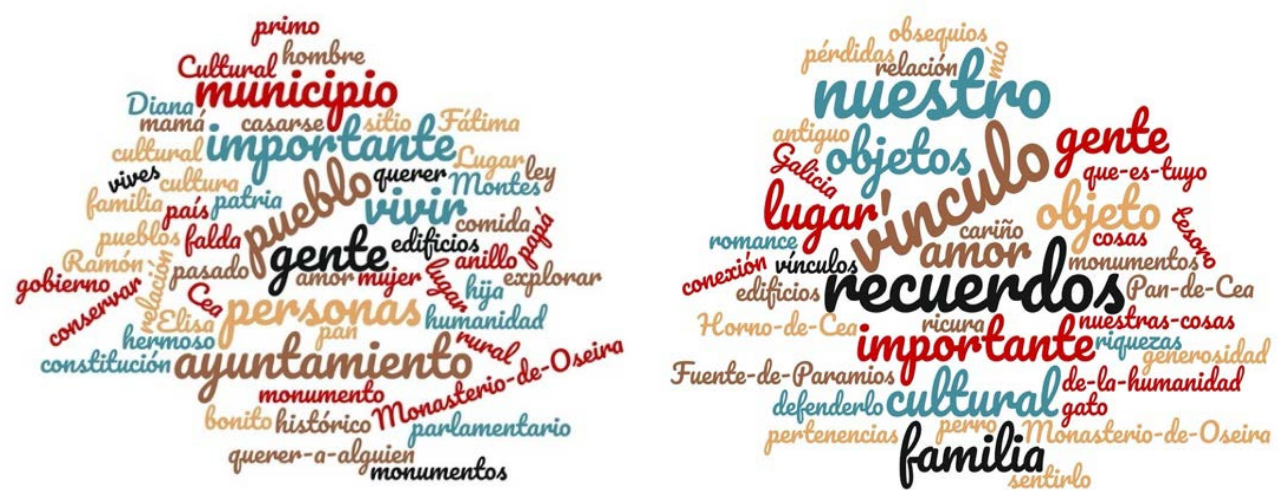

La adquisición de una conceptualización social del patrimonio, también se constata en la selección de dimensiones propuestas para su caracterización (Gráfico 1). La prevalencia objetual se abandona por una de tipo relacional, y la codificación institucional de lo que oficialmente es patrimonio se sustituye por la preferencia de primar los lazos personales para su construcción. Los estudiantes asumen la condición viva y cambiante del patrimonio, en detrimento de la fosilización $\mathrm{y}$ descontextualización hacia una herencia del pasado.

\section{Gráfico 1}

Conceptualización de patrimonio.

El legado (herencia) que nos dejan nuestras familias.

Los bienes patrimoniales que establece la Xunta de Galicia.

Aquellos monumentos, restos arqueológicos, obras de arte... que deben ser conservados por su antigüedad.

Todos aquellos bienes que, por su vínculo con la población, sea considerados por esta de interés.
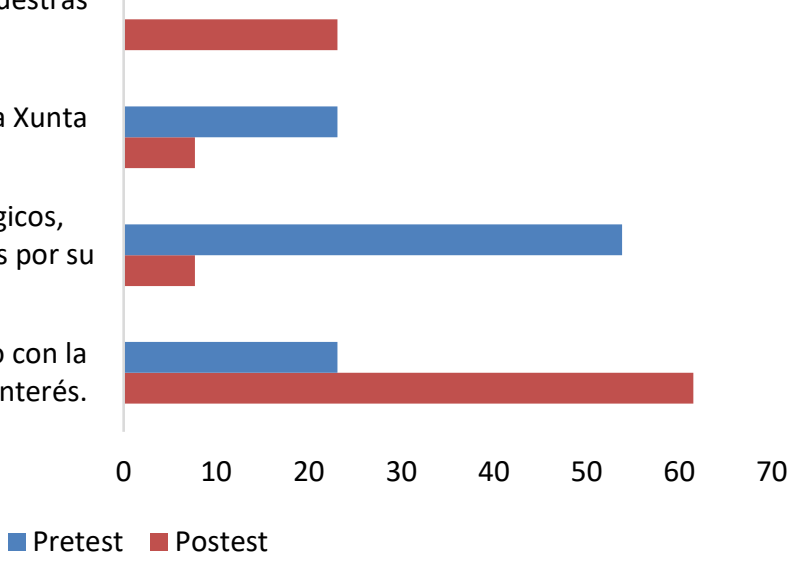
En cuanto a la conveniencia de trabajar el patrimonio en la escuela, la totalidad del alumnado lo ha valorado positivamente, tanto en el pretest como en el postest. Aún así, se observa una evolución analizando y contrastando los resultados en los que la mayoría afirmaba no saber de qué se trataba, manifestando interés en conocerlo, en las primeras etapas, y ratificando su importancia en el postest, ya con conocimientos sobre el tema. La idea que alude a la importancia de saber qué patrimonio nos pertenece se refleja, tácitamente, en tres de las opiniones de los escolares.

La experiencia educativa también fomentó la valoración positiva del entorno al preguntar por lugares a los que los estudiantes llevarían a un amigo/a foráneo/a. Inicialmente señalaron referentes lejanos, pero tras el redescubrimiento de su medio próximo, en especial del monasterio de Oseira, escogieron únicamente elementos de su contexto inmediato, y de manera destacada este cenobio. En su totalidad, el alumnado consideró importante trabajar el patrimonio en el colegio. La mayoría reconoció no saber lo que era antes de la experiencia y ratificó su interés por aprender más sobre él en el postest. También tomó conciencia de su rol en las decisiones sobre el patrimonio local, pues no eran conscientes del papel activo que puede tener la comunidad en su gobernanza y sostenimiento social y cultural (Gráfico 2).

\section{Gráfico 2}

Asignación de responsabilidades sobre el patrimonio local

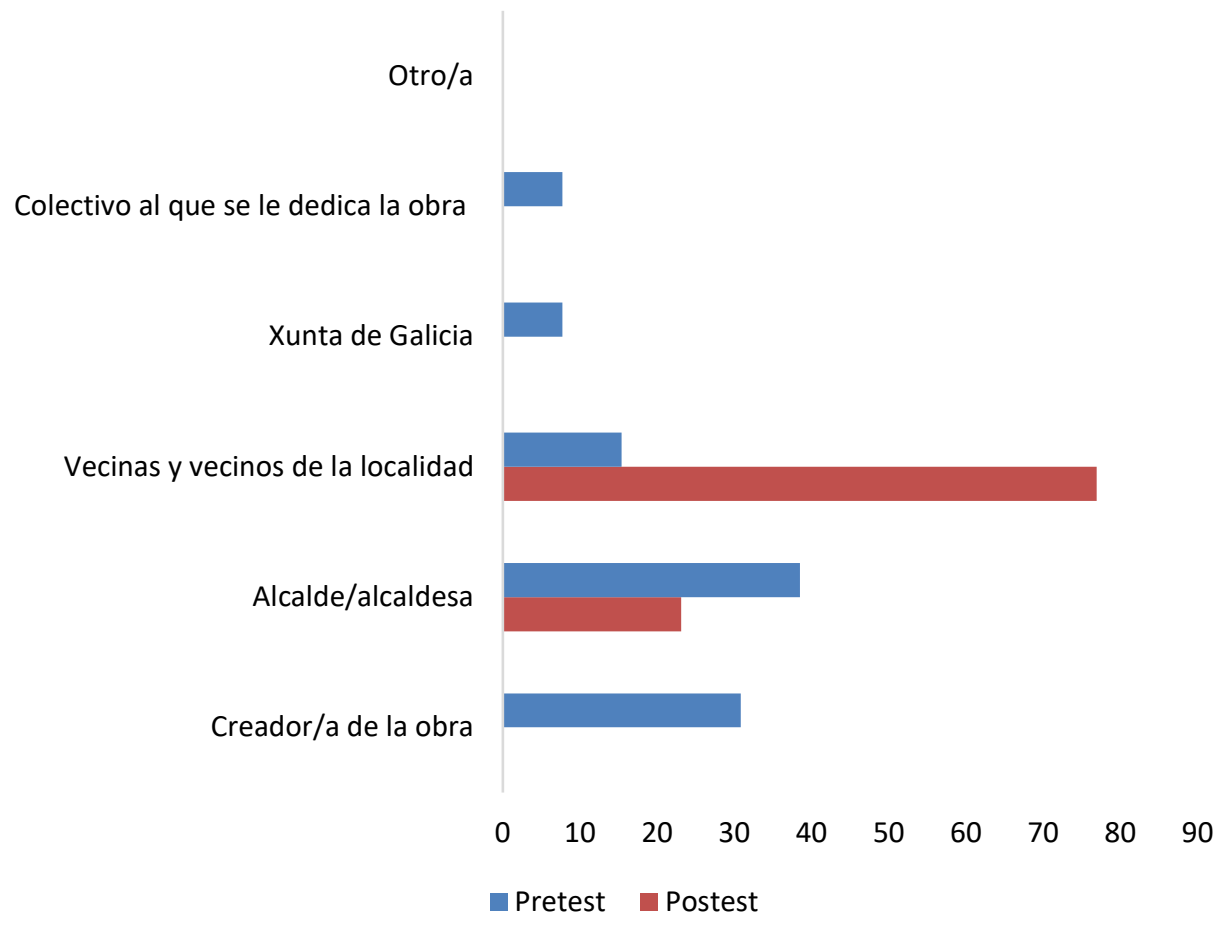




\section{OE2. Desarrollar el pensamiento crítico del alumnado a través de patrimonios conflictivos: el Pazo de Meirás}

Al inicio de la intervención casi la totalidad de los participantes desconocía la existencia del Pazo de Meirás mientras que a su término, tras averiguar su papel relevante en la historia de este lugar, lo vincularon a la escritora Emilia Pardo Bazán (Figura 2). Esto indica que los escolares consideraron que el hecho de haber sido residencia de verano del dictador Franco constituyó una etapa instrumentalizada del edificio de la que prescindieron para aproximarse al redescubrimiento de su contexto original. Aunque los alumnos están inmersos en el mundo de las TIC y Meirás suscita interés mediático casi a diario, la fuente de información proviene mayoritariamente del entorno escolar. Esto refuerza la importancia de trabajar en este tema desde la escuela.

En la asamblea destacaron la importancia de conservarlo para aprender del pasado porque en él "pasaron bastantes cosas y es mejor que la gente sepa el que pasó para que no vuelva a pasar" (I5), "porque es parte de nuestro patrimonio y para dar a conocer su historia" (I9). El desarrollo del pensamiento histórico en la toma de decisiones sobre Meirás, valorando el alcance de los cambios y continuidades sufridas por el conjunto, confluyó en la propuesta de convertirlo en un museo ejemplarizante, no sólo para conservar la memoria de una etapa histórica traumática, sino para recordar los errores cometidos.

\section{Figura 2}

Palabras asociadas con Meirás en pretest (izquierda) y postest (derecha)
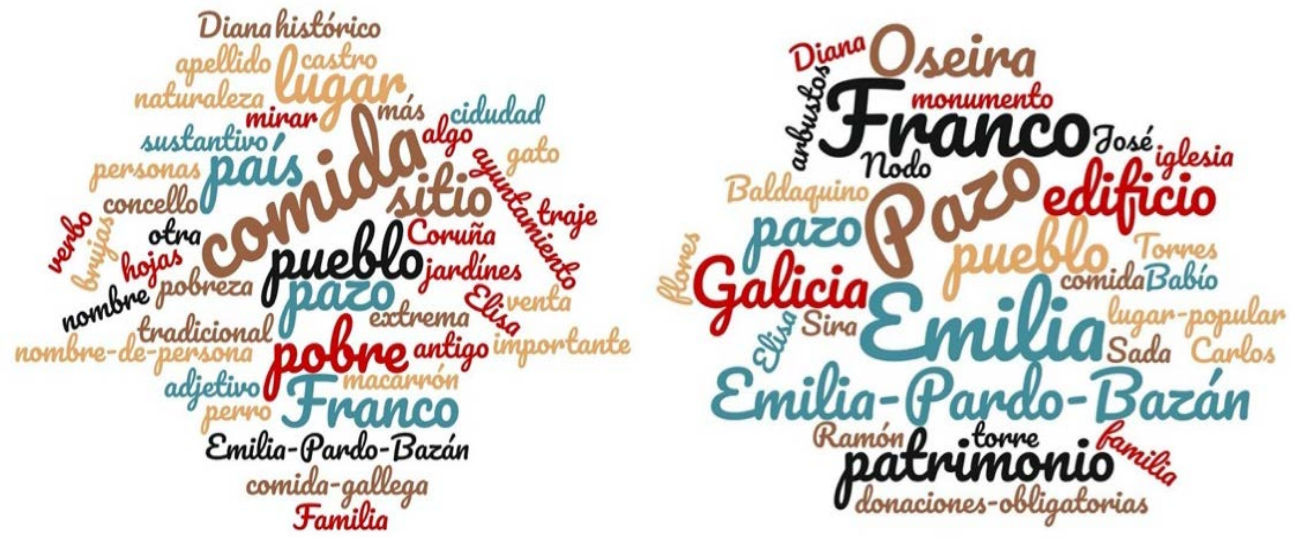

La incidencia de la indagación realizada sobre Meirás y el debate en el aula sobre su futuro, ha favorecido el desarrollo de la competencia patrimonial del alumnado, mediante la búsqueda de información, el contraste de fuentes y la ponderación de diferentes alternativas. El diálogo sobre este patrimonio conflictivo permitió que los escolares comprendieran que la educación proporciona herramientas para mover conciencias y estimular una actitud comprometida con la historia local, aunque sea 
dolorosa. A través de Meirás entendieron que se puede debatir sobre patrimonios incómodos para el desarrollo de una ciudadanía cívica (Tabla 2).

\section{Tabla 2}

Acuerdos tomados en la asamblea escolar sobre el futuro del Pazo de Meirás

\begin{tabular}{|c|c|}
\hline Asunto & Acuerdos redactados por los escolares \\
\hline $\begin{array}{l}\text { Futuro del Pazo } \\
\text { de Meirás }\end{array}$ & $\begin{array}{l}\text { "Decidimos que lo mejor sería abrir un centro de exposiciones para que } \\
\text { la gente supiera todo lo que pasó allí. Lo más justo sería albergar dos } \\
\text { museos en el pazo o dos recorridos: uno para Emilia Pardo Bazán y otro } \\
\text { para Franco, teniendo en cuenta que, en este último, su figura no se } \\
\text { exaltaría, pero diríamos la verdad de lo que sucedió para que no se } \\
\text { repitiera." }\end{array}$ \\
\hline $\begin{array}{l}\text { Compensación } \\
\text { económica del } \\
\text { Estado a la } \\
\text { familia Franco }\end{array}$ & $\begin{array}{l}\text { "Creemos que de ninguna manera se debe premiar a la familia Franco, } \\
\text { porque ya han disfrutado del pazo todos estos años. A pesar de esto, } \\
\text { consideramos que las familias fueron asaltadas y que hicieron las } \\
\text { "donaciones" son recompensadas de alguna manera, ya que existen } \\
\text { registros documentales de esto. Sin embargo, permitiríamos que la } \\
\text { familia del dictador se llevara de la mansión lo que es suyo (como las } \\
\text { cabezas de los animales que cuelgan de la pared y los cuadros del } \\
\text { dictador)." }\end{array}$ \\
\hline $\begin{array}{l}\text { Responsabilidad } \\
\text { de la familia } \\
\text { Franco }\end{array}$ & $\begin{array}{l}\text { "Consideramos que, aunque no tuvieron la culpa de lo que hizo Franco, } \\
\text { se aprovecharon de la situación. Dejaríamos las cosas como están, } \\
\text { siempre que no reclamen nada." }\end{array}$ \\
\hline $\begin{array}{l}\text { Reacción de } \\
\text { expropiados de } \\
\text { Meirás }\end{array}$ & $\begin{array}{l}\text { "Actuaríamos como Carlos Babío. Era la casa de su abuela y no fue justo } \\
\text { lo que le hicieron al arrojarla de esa manera. Creemos que es un acto de } \\
\text { valentía y ejemplo para la familia luchar por la justicia." }\end{array}$ \\
\hline $\begin{array}{l}\text { Reconciliación } \\
\text { de franquistas y } \\
\text { víctimas }\end{array}$ & $\begin{array}{l}\text { "Creemos que debemos escuchar a la gente y, sobre todo, a las víctimas, } \\
\text { tanto del saqueo como del franquismo. También con la familia y } \\
\text { simpatizantes de Franco, para evitar protestas y disturbios. Todos } \\
\text { deben ser escuchados, dentro de la ley, por supuesto. Lo más justo } \\
\text { pensamos es una votación, a nivel gallego, para llegar a un acuerdo con } \\
\text { la suerte de las Torres de Meirás, ya que es parte del patrimonio de todos } \\
\text { los gallegos y gallegas." }\end{array}$ \\
\hline
\end{tabular}

Nota: transcripción literal de los participantes en la asamblea de aula.

\section{OE3. Analizar la re-significación del patrimonio conflictivo local por parte del alumnado mediante una intervención social: la Matanza de Oseira}

Tras el estudio de caso de Meirás, la aproximación a un patrimonio controversial de la localidad, la "Matanza de Oseira", suscitó un proceso de resignificación afectiva y la reivindicación de una historia dolorosa como mecanismo para construir identidad compartida, gestionar pasados conflictivos y satisfacer una deuda moral con los antepasados (Gráfico 3). Bajo este enfoque, se contribuyó al desarrollo de la empatía y a la construcción de una ciudadanía comprometida. Mientras que en el pretest los 
términos con mayor relevancia asociados al monasterio de Oseira se referían a estereotipos como monjes o biblioteca, en el postest el término "baldaquino" adquirió un valor preferente en detrimento de los propuestos en el cuestionario. La experiencia corroboró que la educación patrimonial y la educación histórica no sólo contribuyen a evitar la desafección de la comunidad hacia su patrimonio, sino que proporcionan claves para su comprensión y asignación de referentes contextuales e identitarios, necesarios para su mantenimiento y transmisión.

\section{Gráfico 3}

Re-significación del patrimonio controversial local

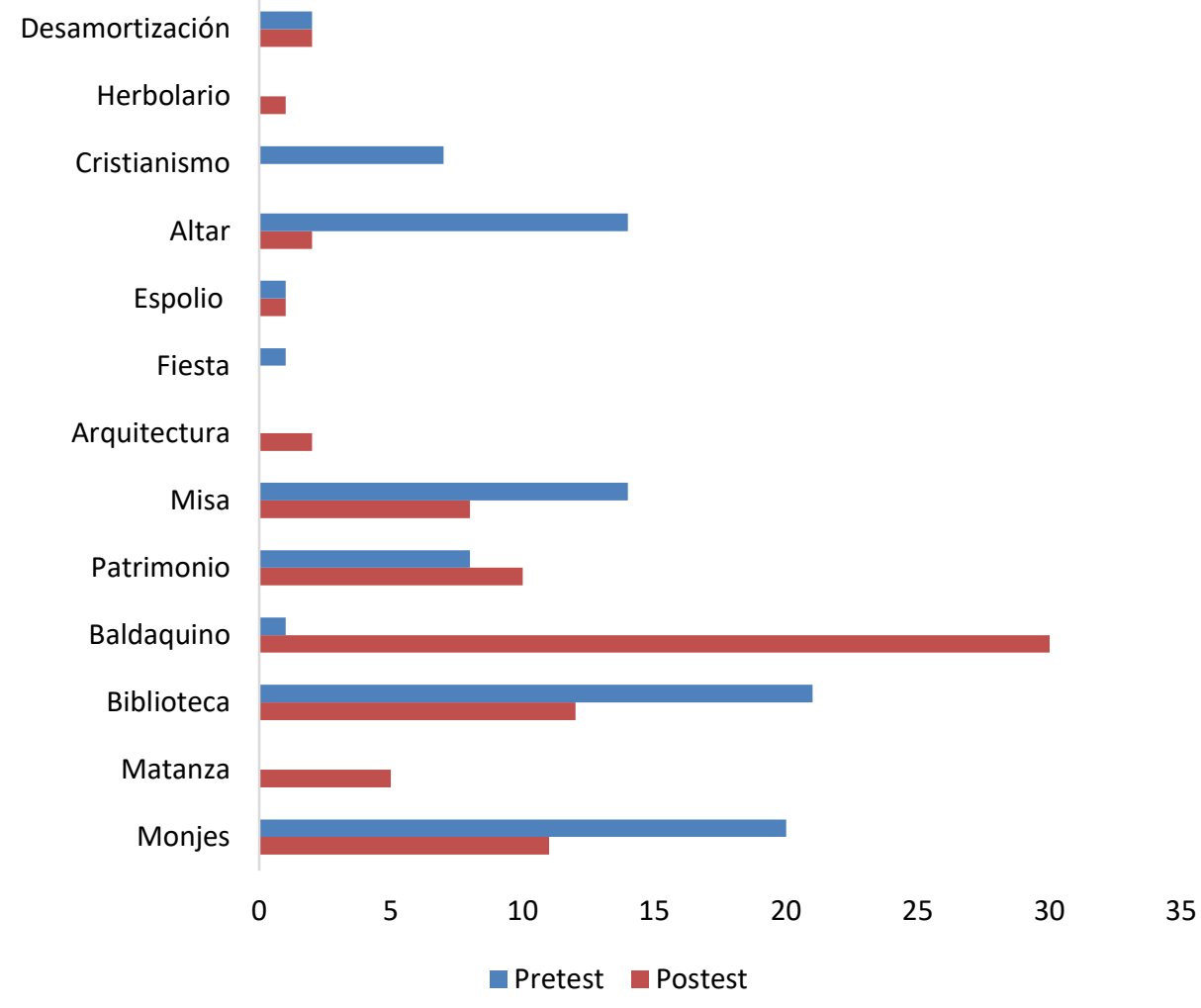

A lo largo de la experiencia educativa los escolares fueron construyendo un discurso más elaborado sobre patrimonio y destacaron que les había despertado su interés hacia el entorno. De hecho, una de las alumnas visitó el monasterio de Oseira con su familia y trajo al aula fotografías de los disparos ocurridos durante la matanza, para incluirlas en el repositorio de recursos. La experiencia fue valorada de manera positiva por haber empleado un modelo de enseñanza reflexivo y comprometido: "hay que conservar el patrimonio y que tiene una historia detrás" (I9); "que el patrimonio es muy importante" (I11); "aprender a apreciar nuestro patrimonio" (I12). Aunque el alumnado puso en valor la conservación del monasterio por su importancia histórico, 
religiosa y artística, ahora saben y conocen la otra historia, que añade un valor intrínseco a su compromiso (Gráfico 4).

\section{Gráfico 4}

\section{Compromiso con la conservación del patrimonio controversial local}

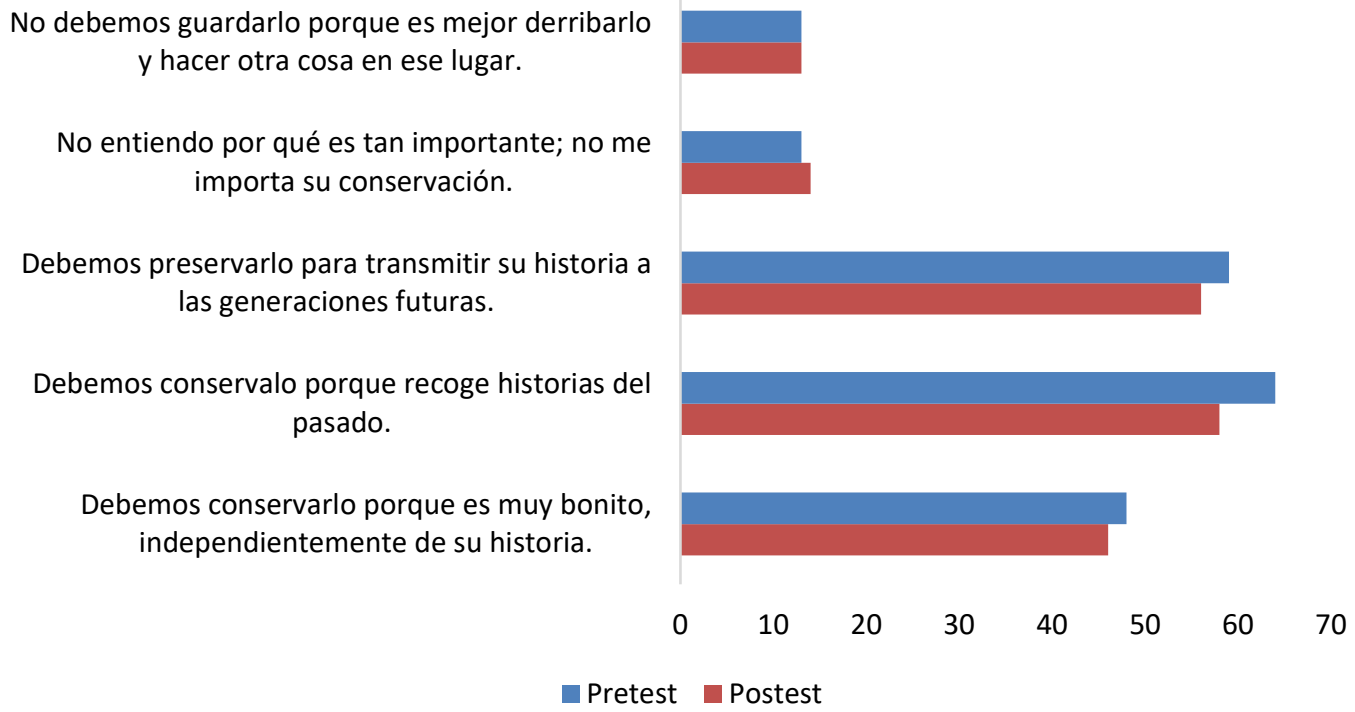

El alcance social de la experiencia educativa se midió a partir de su repercusión social y educacional. La difusión realizada de las diferentes creaciones del alumnado tuvo gran acogida mediática y, en especial, el acto de homenaje a las víctimas en el centro educativo. En este acto, celebrado el día del 112 aniversario del trágico suceso, el alumnado cantó unas coplas de ciego con el acompañamiento musical de un conocido lutier de la localidad. Posteriormente, se descubrió una placa de metacrilato ilustrada con una lámina de Castelao, en recuerdo a las víctimas. Según las palabras del historiador Cabo (2021), estudioso del fatídico suceso, "este homenaje tan modesto desde la escuela es sorprendentemente el primero que se le hace a los Mártires de Oseira en toda su historia" y su repercusión puede ser debida a que "sacó a la luz aspectos olvidados de esta historia y devolvió la dignidad a unos campesinos que pagaron con su vida la defensa del patrimonio" (p. 1).

La transcendencia pública de la intervención de los escolares no consiguió que las figuras representativas de la comunidad eclesiástica, aludidas en la historia, se pronunciasen sobre la Matanza. Con posterioridad a la intervención, el Obispado de Ourense publicó un vídeo sobre lo sucedido, justificando el papel de la Iglesia (Obispado de Ourense, 2021).

Gracias a la repercusión de la experiencia en los medios de comunicación el alumnado asumió su papel activo en la patrimonialización del entorno, un rol del que 
hasta ese momento estaba bastante ajeno. La acogida del proyecto no sólo fue un reconocimiento a su trabajo, sino que contribuyó a reivindicar el papel tanto de las personas en la significación y activación del patrimonio, como el de la educación en la creación de comunidades de aprendizaje fuera de las aulas.

\section{Discusión}

Debido al desconocimiento del alumnado al comienzo de la intervención educativa, sobre el patrimonio, se evidencia la necesidad de una revisión curricular con respecto a los contenidos para la formación patrimonial en los futuros docentes (Fontal et al, 2017; Chaparro y Felices, 2019; Estepa y Delgado, 2021). Asimismo, la investigación asume la secuencia de sensibilización patrimonial sostenida por Fontal $(2003 ; 2020)$, como proceso necesario para conseguir que los ciudadanos conozcan, interpreten, disfruten, conserven, protejan y transmitan su patrimonio. Esta experiencia se enmarca dentro de la línea de patrimonios incómodos que se desarrolla desde el Grupo Roda (USC), lo que contribuye a su consolidación, basándose en diversos estudios que evidencian la conveniencia de tratar conflictos candentes en el aula (López-Facal y Santidrián, 2011); del aprendizaje contextualizado, la vivencia del profesorado en formación junto a la inmersión en un contexto problemático con el pasado traumático para diseñar propuestas de re-significación emocional que contribuyen al aprendizaje significativo así como al desarrollo de herramientas para la gestión pacífica de conflictos (Castro y López-Facal, 2019; Castro, Jiménez et al. 2021; Castro, et al. 2021). Como elemento nuevo, se ha incorporado el "Método Meirás" (Souto, 2019), a modo de estrategia didáctica y modelo de intervención social sobre patrimonio controversial y descontextualizado, para que el alumnado desarrolle las competencias necesarias ante la defensa de su patrimonio. Los escolares aprendieron a emplear el término patrimonio de forma coherente y adecuada a la formación recibida. Con todo, es deseable reforzar la educación patrimonial en el currículum de Primaria, por su contribución competencial y formación de pensamiento socio-crítico. Este estudio también pone en valor la importancia de la implicación del alumnado y, al mismo tiempo, de la crucial colaboración con el resto de la comunidad para participar en la revisión y construcción de una identidad compartida.

Las implicaciones educativas más importantes que se alcanzaron a través de este estudio fueron las siguientes:

- La formación temprana en patrimonio en el alumnado de primaria es relevante para que pueda desarrollar su pensamiento crítico y favorecer su implicación activa en la sociedad.

- La existencia de una formación deficitaria o nula en educación patrimonial, tanto en el alumnado de primaria como en los futuros docentes, conduce a la reflexión sobre la necesidad de aprender e investigar sobre este campo y la propia competencia profesional a fin de diseñar material didáctico propio que permita suplir estas carencias.

- La conveniencia de escoger un modelo adecuado como referente para que el alumnado pueda hacer una analogía en su contexto patrimonial.

- El currículo oculto, en cuanto al tratamiento de temas sociales candentes en el 
aula, tiende a silenciar las polémicas.

- La importancia de la colaboración entre distintos ámbitos de la sociedad (universidad, comunidad educativa, ayuntamiento, medios de comunicación, vecinos...) para la defensa del patrimonio. No habría sido posible realizar esta intervención sin una base científica en la que apoyarse, la excelente disposición del tutor para desenvolver el proyecto en el aula ni la colaboración de las familias, entre otros. Es fundamental la extrapolación de proyectos educativos fuera de las paredes del aula.

Una de las principales limitaciones de este estudio fue el tiempo disponible para su desarrollo. Aun así, es importante recalcar que ni la modestia de los medios utilizados, ni el pequeño número de estudiantes que participaron en la experiencia fueron impedimento para la repercusión social y el interés alcanzado (Figura 3). Resulta significativo que en una situación sociosanitaria de pandemia, con numerosas restricciones, hayan sido capaces de defender su patrimonio local de manera tan relevante; destacando la importancia de la educación patrimonial sobre temas socialmente conflictivos. Su implicación y entusiasmo reabrió el debate sobre un elemento de memoria incómodo, que atrajo el interés de los medios; circunstancia que pudo haber influido en el vídeo que desde el Obispado se publicó sobre el terrible suceso de 1909 justificando el papel de la Iglesia (Obispado de Ourense, 2021). Como línea de futuro, es deseable que desde el centro educativo se dé continuidad a la recuperación de la memoria, como detonante para procesos de activación patrimonial desde la comunidad. Por otra parte, utilizando el conflicto de Meirás, se podría llevar a cabo estrategias metodológicas similares en otros contextos educativos, dirigidas a la intervención social en defensa del patrimonio local, que permitan comprobar la efectividad del modelo de enseñanza aplicado en este estudio.

\section{Agradecimientos}

Este trabajo se desarrolla en el Grupo de Referencia Competitiva GI-1667-RODA (2021PG023) Ref.ED431C 2021/05, de la Universidad de Santiago de Compostela.

\section{Referencias}

AEPD: Agencia Española de Protección de Datos. (2018). Guías sectoriales: Guía para centros educativos. https://www.aepd.es/es/documento/guia-centroseducativos.pdf

de Andrés, J. (2006). Los símbolos y la memoria del Franquismo. Fundación Alternativas. Madrid.

Babío, C., y Pérez, M. (2017). Meirás. Un pazo, un caudillo, un espolio. Santiago de Compostella: Fundación Galiza Sempre.

Cabo, M. (2021). Os Mártires de Oseira: a matanza silenciada/Entrevistado por Cristina Pérez. RTVEG. https://bit.ly/3kZP5Yr

Cabo, M., y Rodríguez, L. J. (2019). Matar un ruiseñor. Oseira 1909, análisis de una masacre. Cuadernos de Historia Contemporánea, 41, 233. https://doi.org/10.5209/chco.66103

Campoy, T., y Gomes, E. (2009). Técnicas e instrumentos cualitativos de recogida de 
datos. Editorial EOS, 284.

Castro, B., y López-Facal, R. (2019). Portomarín: la memoria herida de un desarraigo. Revista Electrónica Interuniversitaria de Formación del Profesorado, 22(2), 95-110. http://dx.doi.org/10.6018/reifop.22.2.363841

Castro, B., Jiménez, G., Marques, L. A. y López, R. (2021). Emotional conflict and trauma: the recovery of stolen memory using a mixed-methods approach. Humanit Soc Sci Commun, 8(1), 1-12. https://doi.org/10.1057/s41599-020$\underline{00684-8}$

Castro, B., López-Facal, R., Jiménez G. y Schugurensky, D. (2021). What can be learned from decontextualised heritage? En C. Gómez, P. Miralles y R. López (eds) Handbook of Research on Teacher Education in History and Geography (pp. 283-308). Peter Lang.

Chaparro, A., y Felices, M. (2019). Percepciones del profesorado en formación inicial sobre el uso del patrimonio en contextos educativos. Revista Interuniversitaria de Formación del Profesorado, 94(33.3), 327-346. https://doi.org/10.47553/rifop.v33i3.74264

Consejo de Europa. (2005). Council of Europe Framework Convention on the Value of Cultural Heritage for Society. Recuperado de: https://rm.coe.int/1680083746

Domínguez, A., y Riveiro, T. (2020). O reto didáctico do conflicto: Pensar e traballar a memoria histórica como educadoras e educadores. Revista Galega de Educación, 76(30-33).

Duch, M. (2002), Toponimia franquista en democracia, en Carlos Forcadell, Carmen Frías, Ignacio Peiró y Pedro Rújula (coords.), Usos Públicos de la Historia. VI Congreso de la Asociación de Historia Contemporánea, CD-Rom, Zaragoza, vol. I. https://ifc.dpz.es/recursos/publicaciones/25/03/ebook2447.pdf

Estepa, J., y Delgado, E. J. (2021). Educación ciudadana, patrimonio y memoria en la enseñanza de la historia: estudio de caso e investigación-acción en la formación inicial del profesorado de secundaria. REIDICS. Revista de Investigación en Didáctica de las Ciencias Sociales, 8, 172-189. https://doi.org/10.17398/2531-0968.08.172

Fernández, F. (2020). Ecosistemas de innovación social-patrimonial. Definición y estudio de casos. PH: Boletín del Instituto Andaluz del Patrimonio Histórico, (99), 64-98. https://doi.org/10.33349/2020.99.4286

Fontal, O. (2003). La educación patrimonial. Teoría y práctica en el aula, el museo e Internet. Trea.

Fontal, O. (2020). El patrimonio. De objeto a vínculo. En. O. Fontal (coord.) Cómo educar en el patrimonio. Guía práctica para el desarrollo de actividades de educación patrimonial (11-25). Comunidad de Madrid.

Fontal, O., Ibáñez, A., Martínez-Rodríguez, M., y Rivero, P. (2017). El patrimonio como contenido en la etapa de Primaria: del currículum a la formación de maestros. Revista electrónica interuniversitaria de formación del profesorado, 20(2), 79-94. http://dx.doi.org/10.6018/reifop.20.1.286321

Fontal, O., y Marín, S. (2018). Nudos Patrimoniales. Análisis de los vínculos de las personas con el patrimonio personal. Arte, Individuo Y Sociedad, 30(3), 483- 
500. https://doi.org/10.5209/ARIS.57754

Freinet, C. (2005). Técnicas Freinet de la escuela moderna. Siglo XXI.

Gómez, C. (2014). Integración de la Educación Patrimonial en la Educación Formal: esbozando la competencia patrimonial. Reflexionar desde las experiencias [Recurso electrónico]: una visión complementaria entre España, Francia y Brasil: actas del II Congreso Internacional de Educación Patrimonial: [28-31 oct. 2014, Madrid] (pp. 1059-1066). Instituto del Patrimonio Cultural de España.

Harvey, D. C. (2001). Heritage pasts and heritage presents: Temporality, meaning and the scope of heritage studies. International journal of heritage studies, 7(4), 319-338. https://doi.org/10.1080/13581650120105534

Jiménez, D., y Felices, M. (2018). Cuestiones socialmente vivas en la formación inicial del profesorado: la infancia refugiada siria como problemática. REIDICS: Revista de Investigación en Didáctica de las Ciencias Sociales, 3, 87102. https://doi.org/10.17398/2531-0968.03.87

Josefsson, J., y Aronsson, I. L. (2016). Heritage as life-values: a study of the cultural heritage concept. Current Science, 2091-2098. http://www.jstor.org/stable/24908138

Ley 52/2007, del 26 de diciembre de 2007, por la que se reconocen y amplían derechos y se establecen medidas a favor de quienes padecieron persecución o violencia durante la guerra civil y la dictadura. Boletín Oficial del Estado, 310. https://www.boe.es/boe/dias/2007/12/27/pdfs/A53410-53416.pdf

López-Facal, R., y Santidrián, V. (2011). Los conflictos sociales candentes en el aula. Íber Didáctica de las Ciencias Sociales, Geografía e Historia, 69, 8-20.

Núñez, X. M. (2019). Que facer cos lugares de ditador? Unha ollada europea. Revista Grial. LVII (229), 14-25.

Núñez, X. M. (2021). Guaridas del lobo. Memorias de la Europa autoritaria, 19452020. Crítica.

Obispado de Ourense (24 de Mayo de 2021). Historia documentada: o baldaquino de Oseira. [Archivo de vídeo]. Youtube. Recuperado de: https://youtu.be/ Zf WpGnSmU

Rina, C. (2019). La memoria franquista en el espacio urbano: cuestiones metodológicas e historiográficas para las comisiones locales de memoria histórica. PH: Boletín del Instituto Andaluz del Patrimonio Histórico, 27(96), 193-196.

Recuperado

de:

https://dialnet.unirioja.es/servlet/articulo?codigo $=6926912$

Rodríguez, P., y López, S. (2013). El conflicto como concepto clave en el aula de Ciencias Sociales en Educación Primaria. Revista de estudios extremeños, 69(3), 1547-1561.

Sánchez, M. F., y Murga, M. A. (2019). Place-based education: una estrategia para la sostenibilización curricular de la educación superior. Bordón. Revista De Pedagogía, 71(2), 155-174. https://doi.org/10.13042/Bordon.2019.68295

Santiesteban, A., y Pagès, J. P. (2011) Didáctica del conocimiento del medio social y cultural en la educación primaria. Síntesis.

Souto, F. (2019). O “método Meirás". O proceso de mobilización cidadá. Revista Grial. LVII (224), 42-49. 
UNESCO, (2012). Exploring Sustainable Development: A Multiple-Perspective Approach. Education for Sustainable Debelopment in Action Learning \& Training. Recuperado de: https://bit.ly/310DZCg

Vygotsky, L. S. (1978). Mind in society: The development of higher psychological processes. Harvard University Press. 